\title{
PENGARUH MODEL TIGA FAKTOR FAMA DAN FRENCH \\ TERHADAP EXPECTED RETURN: STUDI PADA TUJUH SAHAM PERBANKAN KONVENSIONAL DI INDONESIA
}

\author{
Alfi Muflikhah Lestari \\ Setyo Tri Wahyudi \\ Fakultas Ekonomi dan Bisnis \\ Universitas Brawijaya Malang \\ J1. MT Haryono 165 Malang, Telp. 0341-551396 \\ email: alfie.tary@gmail.com, setyo81@gmail.com
}

\begin{abstract}
This research aims to look at the influence of three factors model of Fama and Frencagainst the expected return on a stock of conventional bankaing with seven best performance in Indonesia the period 2010-2014. The data used are secondary data with quantitative research approach by using a classic assumption test. The research result showed that (1) Return the market has a positive influence but not significantly to your expected return, (2) Size SMB has a positive and significant influence against the expected return and (3) Book to market value (HML) has a positive and significant influence against expected return.
\end{abstract}

Keywords: Expected Return, Market Return, Firm size, Book to market

\section{PENDAHULUAN}

erinvestasi di pasar modal merupakan investasi yang memiliki resiko tinggi. Adanya resiko tinggi ini membuat para investor sangat berhati-hati dalam menanamkan modalnya karena setiap investor tentunya ingin mendapatkan keuntungan yang maksimal (expected return). Oleh karena itu, penting bagi investor untuk mendapatkan berbagai informasi mengenai faktor-faktor apa saja yang mempengaruhi pengembalian keuntungan tersebut.

QE Journal | Vol.04 - No.04 December 2015 - 201 


$$
\begin{aligned}
& \mathrm{E}(\mathrm{ri})=\mathrm{rf}+\beta \mathrm{i}(\mathrm{E}(\mathrm{rm})-\mathrm{rf}) \\
& r=r f+\beta 1 f 1+\beta 2 f 2+\beta 3 f 3+\cdot \cdot
\end{aligned}
$$

Pada CAPM (1) menyatakan bahwa investor hanya mendapat kompensasi atas resiko market yang ditanggungnya. Dimana resiko market diukur dengan beta, besaran angka beta menunjukkan berapa besar perubahan return suatu saham terhadap market. Asumsi dasar model CAPM adalah investor menginginkan tingkat return setinggi-tingginya tetapi tidak menyukai resiko. Sedangkan pada model APT (2) beranggapan bahwa returns bisa diprediksi berdasarkan hubungan antar resiko aset yang bersangkutan dan beberapa resiko makro ekonomi. Faktor-faktor resiko aset seperti tingkat pengeluaran konsumen dan risk premium atas sejumlah faktor makro ekonomi seperti tingkat bunga dan pertumbuhan ekonomi.

Fama dan French (1995) selanjutnya mengembangkan model penentuan harga saham dan berpendapat bahwa faktor size dan book to market merupakan faktor dominan dalam memprediksi return. Fama dan French (1995) menduga bahwa size dan book-to-market mungkin merupakan proksi atas faktor resiko yang mempengaruhi return. Size memiliki korelasi negatif dimana semakin kecil kapitalisasi perusahaan memberikan tingkat return yang semakin tinggi sedangkan book-to-market berasosiasi positif yang berarti book-to-market yang tinggi menunjukkan saham yang mengalami undervalue dan memiliki peluang memberikan return lebih tinggi dimasa yang akan datang. Dengan beberapa hasil penelitiannya three factor model Fama dan French dapat dilihat dari persamaan berikut

$$
R_{i t}-R_{f t}=\alpha_{i t}+\beta_{i m}\left(R_{M t}-R_{f t}\right)+\beta_{i s} S M B_{t}+\beta_{i h H M L t}+\varepsilon_{i t}
$$

Dimana $R_{i t}-R_{f t}$ adalah excess return saham yang merupakan selisih return rata-rata saham setelah dikurangi risk free rate. $\beta_{\mathrm{im}}\left(\mathrm{R}_{\mathrm{Mt}}-\mathrm{R}_{\mathrm{ft}}\right)$ merupakan expected market premium, suatu kompensasi atas resiko market yang di tanggung oleh pemegang saham. Angka tersebut merupakan pengurangan market return dengan risk free rate. SMB adalah singkatan dari small minus big. SMB merupakan faktor access return diperoleh dengan menghitung return rata-rata dari perusahaan kecil dikurangi return rata-rata perusahaan besar. HML adalah singkatan dari high minus low. Faktor ini diperoleh dengan mengkalkulasi return rata-rata dari portofolio saham high book to market dikurangi dengan return rata-rata dari portofolio saham dengan low book to market. 
Beberapa penelitian sebelumnya yang berkaitan dengan model tiga faktor dilakukan oleh Davis, Fama dan French (2000) pada United Stated Stock Portfolios selama 816 bulan dengan rentang waktu tahun 1926 - 1997 dengan hasil beta, firm size, dan book to market ratio berhubungan signifikan terhadap return saham (Bodie $Z$, et al 2005). Selanjutnya penelitian Sudiyatno dan Irsad (2011) menunjukan pengaruh positif signifikan antara premi risiko dengan return saham, sedangkan ukuran perusahaan dan book to market ratio berpengaruh negatif, tetapi tidak signifikan terhadap return saham. Selain itu penelitian Ima Triani (2012) menunjukan bahwa faktor book to market (HML) yang berpengaruh signifikan terhadap tingkat pengembalian (expected return), sedangkan risiko pasar (IHSG) dan firm size (SMB) tidak berpengaruh signifikan terhadap expected return. Beberapa penelitian sebelumnya menunjukan tidak semua variabel pada model tiga faktor Fama dan Franch memiliki pengaruh pada return saham.

Pada penelitian ini akan mencoba mengaplikasikan tiga faktor model Fama dan Franch pada saham perbankan. Saham-saham perbankan yang di pilihan adalah pada saham perbankan yang memiliki rasio kinerja terbaik dari periode tahun 2010 - 2014, diantaranya BBCA (Bank Central Asia), BBRI (Bank Rakyat Indonesia), BBTPN (Bank Tabungan Pensiunan Negara), BDMN (Bank Danamon), BMRI (Bank Mandiri), BNGA (Bank CIMB Niaga), dan BBNI (Bank Negara Indonesia). Pemilihan saham perbankan dengan rasio kinerja terbaik ini didasarkan pada (Siamat, 2005):

1) Tingkat profitabilitas, biasa disebut "rentabilitas". Tingkat profitabilitas ini diukur berdasarkan tiga rasio, yakni net interest margin (NIM), return on asset (ROA), dan return on equity (ROE). Semakin tinggi tiga rasio tersebut, maka semakin tinggi kemampuan bank yang bersangkutan dalam mencetak laba.

2) Tingkat kekuatan modal yang diukur dari capital adequacy ratio (CAR). Semakin tinggi CAR, maka semakin kuat modal bank yang bersangkutan. Kuat tidaknya posisi modal suatu bank menentukan kemampuan bank yang bersangkutan dalam berekspansi dan memperluas jaringan usahanya.

3) Pertumbuhan, dimana bank yang bagus adalah yang bertumbuh yakni, modal serta laba bersihnya naik. Semakin besar presentase kenaikannya, maka semakin baik. 
4) Kualitas Kredit, dimana pendapatan utama bank berasal dari bunga kredit/pinjaman yang mereka salurkan, namun pinjaman itu sendiri memiliki risiko tidak di bayar oleh peminjamnya atau disebut kredit macet atau non performing loan (NPL). Semakin besar nilai NPL, maka semakin buruk kulaitas banknya dan sebaliknya. Selain itu rasio yang perlu diperhatikan adalah loan to deposit (LDR) yang menggambarkan jumlah kredit yang disalurkan dibanding DPK yang diterima bank dan sebaliknya.

Oleh karena itu, berdasarkan latar belakang diatas maka pada penelitian ini penulis tertarik melakukan penelitian dengan menggunakan model tiga faktor Fama dan French, yaitu dengan mengetahui pengaruh faktor-faktor penentu tingkat expected return yaitu market, firm size, dan book-to-market pada tujuh saham perbankan konvensional di Indonesia pada periode 2011-2014.

\section{METODE PENELITIAN}

Pada penelitian ini, pendekatan penelitian yang digunakan adalah penelitian kuantitatif. Sumber data yang digunakan adalah data sekunder dengan tipe data runtut waktu (time series). Data runtut waktu (time series) merupakan sekumpulan observasi data yang dikumpulkan dalam interval waktu secara kontinu. Tahun yang dijadikan sebagai data analisis adalah tahun 2010- 2014.

Populasi dari penelitian ini adalah Jakarta Stock Exchange Composite Index (JKSE), Bursa Efek Indonesia dan Bank Indonesia. Sample yang digunakan terdiri dari tujuh saham perbankan dengan rasio kinerja terbaik yaitu $B C A$, BRI, BTPN, DANAMON, MANDIRI, CIMB NIAGA, BNI dengan kurun waktu 2010 - 2014 yang diambil berdasarkan purposive sampling.

\section{Definisi Operasional}

Menurut Nazir (2005) definisi operasional merupakan suatu definisi yang diberikan kepada suatu variabel atau konstrak dengan cara memberikan arti, atau menspesifikasikan kegiatan ataupun memberikan suatu operasional yang diperlukan untuk mengukur konstrak atau variabel tersebut. Berdasarkan konsep di atas, definisi operasional dalam penelitian ini dijabarkan sebagai berikut:

QE Journal | Vol.04 - No.04 December 2015 - 204 
Tabel 1: Definisi dan Pengukuran Variabel Penelitian

\begin{tabular}{|c|c|c|}
\hline Variabel & Pengukuran & Keterangan \\
\hline $\begin{array}{l}\text { Expected } \\
\text { Return }\end{array}$ & $\begin{array}{lrr}\text { Expected } & \text { Excess } & \text { return } \\
\text { Saham } & =\text { rata-rata } & \text { return } \\
\text { bulanan } & \text { portofolio } \\
\text { Rf/month } & & \end{array}$ & $\begin{array}{l}\text { Selisih dari return portofolio } \\
\text { bulanan dengan risk free rate } \\
\text { bulanan }\end{array}$ \\
\hline Market Return & $\begin{array}{lr}\text { Market return } & = \\
\text { rataratareturn } & \text { bulanan } \\
\text { dari seluruh } & \text { saham- } \\
\text { Rf/month } & \end{array}$ & $\begin{array}{l}\text { Selisih dari average setiap } \\
\text { bulan dariseluruh saham } \\
\text { dengan risk-free rate bulanan }\end{array}$ \\
\hline $\begin{array}{l}\text { Small Minus Big } \\
\text { (SMB) }\end{array}$ & $\begin{array}{l}\mathrm{SMB}=\quad \text { (average } \\
\text { returnsetiap bulan } \mathrm{S} / \mathrm{L}+ \\
\mathrm{S} / \mathrm{M}+\mathrm{S} / \mathrm{H})-(\text { averagereturn } \\
\text { setiap bulan } \mathrm{B} / \mathrm{L}+\mathrm{B} / \mathrm{M}+ \\
\mathrm{B} / \mathrm{H})\end{array}$ & $\begin{array}{l}\text { Selisih dari average setiap } \\
\text { bulan return perusahaan } \\
\text { small dengan average } \\
\text { setiapbulan } \\
\text { returnperusahaan big. }\end{array}$ \\
\hline $\begin{array}{l}\text { High Book-to Market } \\
\text { Equity minus Low } \\
\text { Book-to Market } \\
\text { Equity (HML) }\end{array}$ & $\begin{array}{l}\mathrm{HML}=\quad \text { (average } \\
\text { returnsetiap bulan } \mathrm{S} / \mathrm{H}+ \\
\mathrm{B} / \mathrm{H})-\quad(\text { average return } \\
\text { setiapbulan } \mathrm{S} / \mathrm{L}+\mathrm{B} / \mathrm{L})\end{array}$ & $\begin{array}{l}\text { Selisih dari average setiap } \\
\text { bulan return perusahaan } \\
\text { dengan high book-to-market } \\
\text { equity dengan averagesetiap } \\
\text { bulan returnperusahaan } \\
\text { dengan low book-to-arket } \\
\text { equity. }\end{array}$ \\
\hline
\end{tabular}

Sumber: Berbagai sumber diolah (2016)

\section{Metode Analisis Data}

Menurut Sugiyono (2012), kegiatan dalam analisis data adalah pengelompokan data berdasarkan variabel dan jenis responden, mentabulasi data berdasarkan variabel yang diteliti, melakukan perhitungan untuk menjawab rumusan masalah, dan melakukan perhitungan untuk menguji data yang telah dikumpulkan. Pada penelitian ini analisis yang digunakan adalah uji asumsi klasik dengan model penelitian dinyatakan sebagai berikut:

$$
R_{\mathrm{it}}-\mathbf{R}_{\mathrm{ft}}=\alpha_{\mathrm{it}}+\beta_{\mathrm{im}}\left(\mathrm{R}_{\mathrm{Mt}}-\mathrm{R}_{\mathrm{ft}}\right)+\beta_{\mathrm{is}} \mathrm{SMB}_{\mathrm{t}}+\beta_{\mathrm{ih}} \mathrm{HML}_{\mathrm{t}}+\varepsilon_{\mathrm{it}}
$$


Keterangan

$\mathbf{R}_{\mathbf{i t}}-\mathbf{R}_{\mathbf{f t}} \quad$ : Expected Excess Return

$\mathbf{R}_{\mathrm{Mt}}-\mathbf{R}_{\mathrm{ft}} \quad$ : Market Return

SMB : Return Small Minus Big

HML : Return High Minus Low

$\alpha_{\text {it }} \quad$ : Konstanta

$\beta_{\text {im, }} \beta_{\text {is, }} \beta_{\text {ih }}$ : Koefisien Regresi

$\varepsilon_{\text {it }} \quad$ : Error Term

\section{Hasil dan Pembahasan}

\section{Uji Asumsi Klasik}

Pengujian normalitas dilakukan untuk mengetahui apakah data yang telah diperoleh berdistribusi normal. Pada program E-views hal tersebut dapat dilakukan dengan melihat uji Jarque-Bera Test, dan pada penelitian ini hasil uji normalitas, adalah sebagai berikut

\section{Tabel 2: Hasil Uji Normalitas}

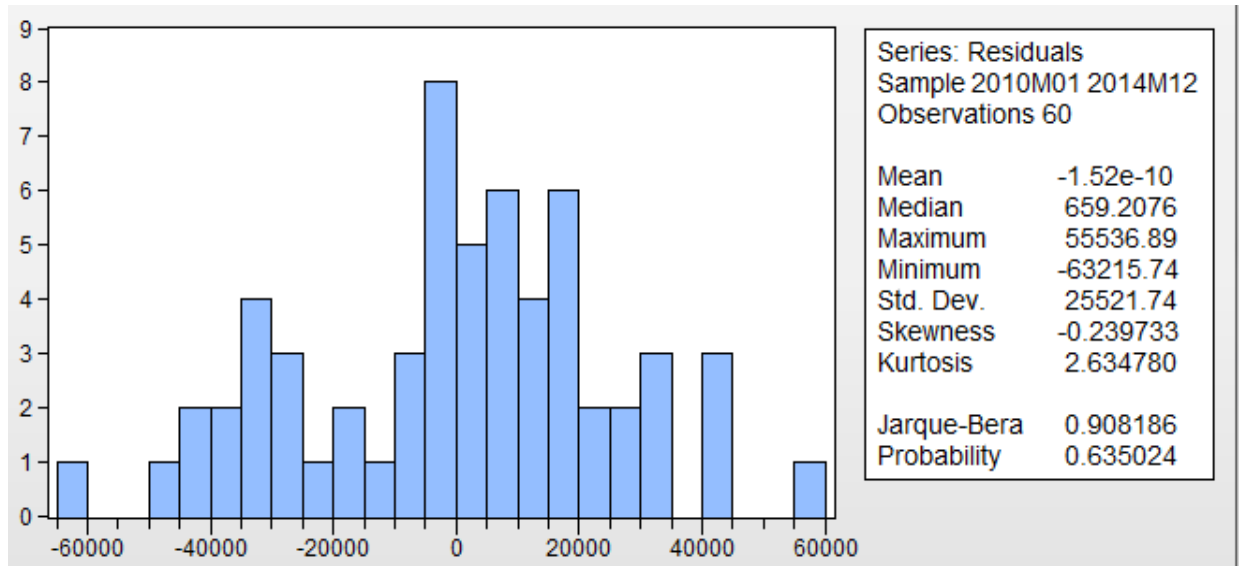

Sumber: Data diolah, 2016

Pada hasil uji diatas dapat dilihat nilai Jarque-Bera menunjukkan angka 0.908186 dimana angka ini lebih besar dari tingkat signifikansi $\alpha=5 \%$, 
yang artinya bahwa data yang digunakan sudah signifikan dan telah terdistribusi secara normal.

Pengujian multikolinearitas dilakukan untuk menguji apakah model regresi ditemukan adanya korelasi antar variabel bebas (independen). Uji multikolinearitas dilakukan dengan menggunakan Correlation Matrix dari variabel bebas, sebagai berikut

Tabel 3: Hasil Uji Multikolinearitas

\begin{tabular}{|l|l|l|l|}
\hline & ReturnPasar & SMB & HML \\
\hline ReturnPasar & 1.000000 & 0.533863 & 0.717233 \\
\hline SMB & 0.533863 & 1.000000 & 0.577670 \\
\hline HML & 0.717233 & 0.577670 & 1.000000 \\
\hline
\end{tabular}

Sumber: Data diolah, 2016

Pada tabel 3 diatas, dapat diketahui bahwa tidak ada masalah multikolinearitas, hal ini dikarenakan nilai matriks korelasi dari semua variabel adalah kurang dari 0,8 .

Pengujian autokorelasi dilakukan karena adanya masalah serial korelasi akibat residual tidak bebas dari suatu observasi ke observasi lainnya. Masalah tersebut sering ditemukan pada data time series. Pada E-views, uji autokorelasi dijelaskan pada hasil Uji Breusch-Godfrey (LM Test) adalah sebagai berikut.

\section{Tabel 4: Hasil Uji Autokorelasi}

Breusch-Godfrey Serial Correlation LM Test:

\begin{tabular}{llll}
\hline \hline F-statistic & 0.720716 & Prob. F(2,54) & 0.4910 \\
Obs*R-squared & 1.559950 & Prob. Chi-Square(2) & 0.4584 \\
\hline
\end{tabular}

Test Equation:

Dependent Variable: RESID

Method: Least Squares

Date: 01/03/16 Time: 11:19

Sample: 2010M01 2014M12

Included observations: 60 
Presample missing value lagged residuals set to zero.

\begin{tabular}{|c|c|c|c|c|}
\hline Variable & Coefficien & tStd. Error & $\mathrm{t}$-Statistic & Prob. \\
\hline C & 0.476442 & 4.622364 & 0.103073 & 0.9183 \\
\hline Return Pasar & 2.01E-05 & 0.000528 & 0.038182 & 0.9697 \\
\hline SMB & 0.009810 & 0.353465 & 0.027755 & 0.9780 \\
\hline HML & -0.114909 & 0.995456 & -0.115433 & 0.9085 \\
\hline $\operatorname{RESID}(-1)$ & -0.016154 & 0.135074 & -0.119592 & 0.9053 \\
\hline $\operatorname{RESID}(-2)$ & -0.163529 & 0.136602 & -1.197116 & 0.2365 \\
\hline R-squared & 0.025999 & \multicolumn{2}{|c|}{ Mean dependent var } & $1.31 \mathrm{E}-15$ \\
\hline Adjusted R-squared & -0.064186 & \multicolumn{2}{|c|}{ S.D. dependent var } & 3.261686 \\
\hline S.E. of regression & 3.364736 & \multicolumn{2}{|c|}{ Akaike info criterion } & 5.359216 \\
\hline Sum squared resid & 611.3582 & \multicolumn{2}{|c|}{ Schwarz criterion } & 5.568650 \\
\hline Log likelihood & -154.7765 & \multicolumn{2}{|c|}{ Hannan-Quinn criter. } & 5.441137 \\
\hline F-statistic & 0.288286 & \multicolumn{2}{|c|}{ Durbin-Watson stat } & 1.890798 \\
\hline Prob(F-statistic) & 0.917465 & & & \\
\hline
\end{tabular}

Sumber: Data diolah, 2016

Pada hasil tabel 4 diatas, nilai prob chi-square sebesar 0. 4584. Dimana nilai ini lebih besar dari tingkat signifikansi $\alpha=5 \%$, berarti tidak terjadi masalah autokorelasi.

Pengujian heteroskedastisitas dilakukan bertujuan menguji apakah dalam model regresi terjadi ketidaksamaan varians dari residual satu pengamatan ke pengamatan lain. Heteroskedastiditas terjadi apabila variabel gangguan tidak mempunyai varians yang samauntuk semua observasi. Hasil uji heteroskedastisitas dijelaskan pada hasil Uji White, sebagai berikut:

Tabel 5: Hasil Uji Heteroskedastisitas

Heteroskedasticity Test: White

\begin{tabular}{lclc}
\hline \hline F-statistic & 1.890729 & Prob. F(3,56) & 0.1416 \\
Obs*R-squared & 5.518390 & Prob. Chi-Square(3) & 0.1375 \\
Scaled explained SS & 12.60998 & Prob. Chi-Square(3) & 0.0056 \\
& QE Journal & Vol.04 - No.04 December 2015 - 208
\end{tabular}


Test Equation:

Dependent Variable: RESID ${ }^{\wedge} 2$

Method: Least Squares

Date: 01/03/16 Time: 11:20

Sample: 2010M01 2014M12

Included observations: 60

\begin{tabular}{lcccc}
\hline \hline Variable & \multicolumn{2}{c}{ Coefficient Std. Error } & t-Statistic & Prob. \\
\hline \hline C & -3.959802 & 16.10039 & -0.245944 & 0.8066 \\
Return Pasar^2 & $-2.15 E-07$ & $1.81 E-07$ & -1.185707 & 0.2407 \\
$\mathrm{SMB}^{\wedge}$ & -0.341892 & 0.204173 & -1.674519 & 0.0996 \\
$\mathrm{HML}^{\wedge} 2$ & 1.138298 & 0.555530 & 2.049030 & 0.0452 \\
\hline \hline R-squared & 0.091973 & Mean dependent var & 10.46129 \\
Adjusted R-squared & 0.043329 & S.D. dependent var & 24.16374 \\
S.E. of regression & 23.63445 & Akaike info criterion & 9.227628 \\
Sum squared resid & 31280.87 & Schwarz criterion & 9.367251 \\
Log likelihood & -272.8288 & Hannan-Quinn criter. 9.282242 \\
F-statistic & 1.890729 & Durbin-Watson stat & 2.044003 \\
Prob(F-statistic) & 0.141632 & & & \\
\hline \hline
\end{tabular}

Sumber: Data diolah, 2016

Dengan melihat prob Obs ${ }^{*} \mathrm{R}$-squared $=\mathbf{0 . 1 3 7 5}$ dimana lebih dari $\alpha=5 \%$, maka dengan tingkat keyakinan 99\% tidak terjadi masalah heteroskedastisitas.

\section{Pengujian Model}

Pengujian model yang harus dilakukan, yakni dengan uji koefisien $\left(\mathrm{R}^{2}\right)$, uji F, dan uji t. Hasil Uji Goodness of fit, sebagai berikut:

\section{Tabel 6: Hasil Uji Goodness of fit}

Dependent Variable: Expected Return

Method: Least Squares 
Date: 01/03/16 Time: 11:15

Sample: 2010M01 2014M12

Included observations: 60

\begin{tabular}{lllll} 
Variable & Coefficient & Std. Error & t-Statistic & Prob. \\
\hline \hline Return Pasar & 3.708770 & 5.706952 & 0.649869 & 0.5184 \\
SMB & 116.4939 & 21.58460 & 5.397081 & 0.0000 \\
HML & 70.99878 & 4.985625 & 14.24070 & 0.0000 \\
C & 249216.4 & 11159.23 & 22.33276 & 0.0000 \\
\hline \hline & & & \\
R-squared & 0.896140 & Mean dependent var & 447319.7 \\
Adjusted R-squared & 0.890577 & S.D. dependent var & 80380.71 \\
S.E. of regression & 26589.31 & Akaike info criterion & 23.27875 \\
Sum squared resid & $3.96 E+10$ & Schwarz criterion & 23.41837 \\
Log likelihood & -694.3624 & Hannan-Quinn criter. & 23.33336 \\
F-statistic & 161.0632 & Durbin-Watson stat & 0.461593 \\
Prob(F-statistic) & 0.000000 & & \\
\hline \hline
\end{tabular}

Sumber: Data diolah, 2016

Berdasarkan hasil regresi diatas, menunjukkan market return, SMB, dan HML memiliki hubungan yang positif dengan expected excess return. Model persamaan regresi yang dihasilkan sebagai berikut :

$$
\text { Expected Return }=3.708770(\text { ReturnPasar })+116.4939(\mathrm{SMB})+70.99878(\mathrm{HML})
$$

Dalam hasil regresi di atas, nilai $R$-Square menunjukkan angka 0.896140 atau $89 \%$. Hal ini berarti sebesar $89 \%$ dari variabel independen mampu menjelaskan varibel dependennya yaitu market return, SMB, dan HML terhadap expected excess return. Dan sisanya yaitu sebesar $11 \%$ dijelaskan oleh variabel lain diluar model.

Pada hasil regresi di atas nilai F-statistik menunjukkan angka 161.0632. Dalam hal ini F-Hitung $>$ F-Tabel $=161.0632>3.16$, maka variabel 
independen yaitu market return, SMB, dan HML berpengaruh secara bersama-sama terhadap variabel dependennya yaitu expected excess return. Sedangkan uji $t$, hasil regresi di atas dapat disimpulkan bahwa variabel SMB dengan nilai probabilitas sebesar $\mathbf{0 . 0 0 0 0}$ dan variabel HML dengan nilai probabilitas sebesar $\mathbf{0 . 0 0 0 0}$ berpengaruh secara signifikan terhadap expected excess return. Sedangkan returnpasar dengan nilai probabilitas sebesar $\mathbf{0 . 5 1 8 4}$ memiliki pengaruh yang tidak signifikan terhadap expected excess return dikarenakan standar deviasinya lebih dari $\alpha=5 \%$.

\section{Kaitan antara Return Pasar dengan expected return}

Besarnya koefisien return pasar adalah 0.649869 sehingga bertanda positif dengan nilai probabilitasnya sebesar 0.5184, yang artinya terdapat pengaruh positif namun tidak signifikan antara return pasar terhadap expected return, pada tinggkat signifikansi kurang dari $1 \%$. Dengan demikian, maka semakin tinggi return pasar, maka belum tentu expected return saham akan tinggi.

Hasil penelitian ini sama dengan penelitian Ima Triani (2012) yang menunjukan bahwa risiko pasar tidak memiliki pengaruh signifikan terhadap expected return. Nilai koefisien return pasar menunjukkan arah yang positif tetapi tidak signifikan, maka jika return pasar naik, belum tentu akan dikuti oleh kenaikan expectedreturn saham. Return pasar dalam hal ini adalah merupakan risk premium pada protofolio pasar yang menggambarkan besar kecilnya risiko. Pada penelitian ini, jika risk premium tinggi, maka belum dapat dipastikan risiko investasi juga tinggi. Hal ini

dikarenakan pada periode penelitian antara tahun 2010 -2014 saham-saham perbankan dengan kinerja terbaik seharusnyaberesiko tinggi namun belum dapat di pastikan akan menghasilkan tingkat pengembalian sahamnya akan tinggi pula.

\section{Kaitan antara SMB dengan expected return}

Besarnya koefisien return pasar adalah 5.397081 sehingga bertanda positif dengan nilai probabilitasnya sebesar 0.0000, yang artinya terdapat pengaruh positif dan signifikan antara size SMB terhadap expected return, pada tinggkat signifikansi kurang dari $1 \%$. 
Hasil penelitian ini sama dengan Davis, Fama dan French (2000) dengan hasil firm size berhubungan signifikan terhadap return saham (Bodie Z, et al 2005). Size SMB merupakan ukuran perusahaan yang merepresentasikan return portofolio saham kecil (firm size kecil) dengan portofolio saham besar (firm size besar), dan diproksi dengan nilai kapitalisasi pasar modal sendiri.

Nilai koefisien size SMB menunjukkan arah yang positif dan signifikan, maka artinya signifikannya nilai kapitalisasi pasar terhadap expected returnsaham menunjukkan bahwa investor menggunakan indikator ini sebagai dasar pengambilan keputusan untuk investasinya. Saham-saham perbankan yang digunakan pada penelitian ini menunjukan kinerja yang baik selama periode 2010 - 2014 sehingga investor tertarik untuk melakukan investasi pada saham-saham tersebut.

\section{Kaitan antara HML dengan expected return}

Besarnya koefisien book to market value (HML) adalah 14.24070 bertanda positif dengan nilai probabilitasnya sebesar 0.0000 , yang artinya terdapat pengaruh positif dan signifikan antara book to market value (HML) terhadap expected return, pada tinggkat signifikansi kurang dari $1 \%$.

Hasil penelitian ini sama dengan penelitian yang dilakukan oleh Ima Triani (2012) yang menunjukan bahwa faktor book to market (HML) berpengaruh signifikan terhadap tingkat pengembalian. Book-to-market value(HML) disini merepresentasikan return portofoliosaham dengan book-to-market ratio tinggi denganbook-to-market ratio rendah yang diproksi dengannilai buku (shareholders equity) dibagi denganharga pasar saham.

Nilai koefisien book to market (HML) menunjukkan arah yang positif dan signifikan, maka apabila book to market ratio naik maka expected returnsaham akan naik. Hal ini menunjukkan tingkat optimisme investor terhadap masa depan perusahaan semakin baik.

\section{Kesimpulan}

Berdasarkan hasil penelitian yang dilakukan maka dapat disimpulkan, bahwa (1) Return Pasar memiliki pengaruh yang positif tetapi tidak signifikan terhadap expected return, (2) Size SMB memiliki pengaruh positif dan signifikan terhadap expected return, dan (3) Book to market value 
(HML) memiliki pengaruh positif dan signifikan terhadap expected return. Oleh karena itu, keseluruhan variabel three faktor model Fama dan French terbukti memiliki pengaruh terhadap expected return saham perbankan konvensional dalam periode 2010-2014.

Kinerja perbankan yang baik akan membuat saham perbankan di minati oleh para investor sehingga perbankan perlu meningkatkan kinerjanya. Bagi para investor yang akan melakukan investasi pada saham perbankan tentu harus memilih saham-saham perbankan yang memberikan keuntungan lebih dengan cara mempertimbangkan terlebih dahulu ketika akan memutuskan berinvestasi dengan melihat adanya return saham, firm size, dan book to marketseperti yang telah dirumuskan pada model tiga faktor Fama dan French.

\section{DAFTAR PUSTAKA}

Bank Indonesia. 2015. "Market Data dan Info". www.bi.go.id. Diakses 30 Desember 2015.

Bursa Efek Indonesia. 2015. "IDX Fact Book". www.idx.co.id. Diakses 30 Desember 2015.

Bodie, Z. Kane, A, Marcus. AJ. 2005. "Investment". Terjemahan Zuliani D dan Budi Wiboeo. Jakarta Salemba Empat.

Ghozali, Imam. 2006. Aplikasi Analisis Multivariate dengan Program SPSS. Semarang : Universitas Diponegoro.

Fama, French. 1992. "The Cross-Section of Expected Stock Return". Journal of Finance, Volume 47 Nomor 2.

Fama, French. 1995. "Size and Book to Market Factors in Earning and Return". Journal of Finance, Volume 50 Nomor 2

Jakarta Composite Index. 2015. "Historical Price". www.investing.com. Diakses 30 Desember 2015.

Nazir, Muhammad. 2005. Metode Penelitian. Jakarta : Ghalia Indonesia

Sugiyono. 2012. Metode Penelitian Kuantitatif Kualitatif Dan R \& D. Cetakan ke 17. Bandung: CV. Alfabeta 
Sudiyatno, Bambang. Irsad, Moch. 2011. “Menguji Model Tiga Faktor Fama dan French Dalam Mempengaruhi Return Saham Studi Pada Saham LQ45 Di Bursa Efek Indonesia". Jurnal Bisnis dan Ekonomi September 2011 Hal 126-136 Volume 18 No 2.

Susanti, Neneng. 2013. "Pengujian Fama French Three Factor Model Pada Perusahaan Di Indonesia Yang Sahamnya Terdapat di LQ 45 Tahun 2005 - 2009". Jurnal Forum Keuangan dan Bisnis II.

Siamat, Dahlan.2005."Manajemen Lembaga Keuangan Kebijakan Moneter dan Perbankan.".Edisi kelima.Jakarta:Lembaga Penerbit Fakultas Ekonomi Universitas Indonesia

Triani, Ima. "Analisis Pengaruh Three Factor Model Fama dan French Terhadap Expected Return Pada Reksa Dana Top Five Star Monthly Data Periode 2009 - 2011". Skripsi Di Terbitkan. Yogyakarta : Universitas Atma Jaya 